\title{
Impact on prostate cancer clinical presentation after non-screening policies at a tertiary-care medical center- a retrospective study
}

\author{
Tarek Ajami $^{1 \dagger}$, Jaime Durruty ${ }^{2 \dagger}$, Claudia Mercader ${ }^{1}$, Leonardo Rodriguez ${ }^{3}$, Maria J. Ribal ${ }^{1}$, Antonio Alcaraz ${ }^{1}$ \\ and Antoni Vilaseca ${ }^{1 *}$
}

\begin{abstract}
Background: In May 2012 the US Preventive Task Force issued a'D' recommendation against routine PSA-based early detection of prostate cancer. This recommendation was implemented progressively in our health system. The aim of this study is to define its impact on prostate cancer staging at a tertiary care institution.

Methods: A retrospective analysis was performed from 2012 until 2015 at a single center. We analyzed the total number of biopsies performed per year and the positive biopsy rate. For those patients with positive biopsies we recorded diagnostic PSA, clinical stage, ISUP grade group, nodal involvement and metastatic status at diagnosis.

Results: A total of 1686 biopsies were analyzed. The positive biopsy rate increased from 25\% in 2012 to $40 \%$ in 2015 $(p<0.05)$. No change in median PSA was noticed $(p=0.627)$. The biopsies detected higher ISUP grades $(p=0.000)$. In addition, newly diagnosed prostate cancer presented a higher clinical stage $(p=0.005)$, higher metastatic rates ( $p=0.03$ ) and a tendency to higher lymph node involvement although not statistically significant $(p=0.09)$.
\end{abstract}

Conclusion: After the 2012 recommendation, patients presented a higher probability of a prostate cancer diagnosis, with a more adverse ISUP group, clinical stage and metastatic disease.

These results should be taken into consideration to implement a risk adapted strategy for prostate cancer screening.

Keywords: Prostate cancer, Prostate specific antigen, Prostate cancer screening

\section{Background}

Prostate cancer is the second most commonly diagnosed and the most prevalent cancer among males, with 358,989 deaths worldwide during 2018 [1]. Since the introduction of PSA-based prostate cancer screening in the late 1980s, the prostate cancer incidence increased considerably and reductions of up to $50 \%$ in mortality

\footnotetext{
*Correspondence: AVILASEC@clinic.cat

†Tarek Ajami and Jaime Durruty have contributed equally to this work

1 Urology Department, Hospital Clínic de Barcelona, C/ Villarroel, 170,

08036 Barcelona, Spain

Full list of author information is available at the end of the article
}

were reported [2-6]. However, the increased diagnosis also portends an increased overdiagnosis and overtreatment [7-9] with its related complications (mainly anxiety, sepsis, urinary incontinence and erectile dysfunction) [10-12]. The risk/benefit of prostate cancer screening became, and continues to be, a controversial topic.

In May 2012 the US Preventive Task Force (USPTF) issued a 'D' recommendation for routine PSA-based early detection of prostate cancer, stating that it should not be offered in the general U.S. population, regardless of age [13]. This recommendation was based on the results of two randomized trials willing to prove whether screening 
could reduce prostate cancer mortality. The "Prostate, Lung, Colorectal, and Ovarian (PLCO)" screening trial, in which 76,685 men between 55 and 74 years were randomized to either annual PSA screening and digital rectal examination for 6 years or 'usual care', showed no mortality advantage at 10 years follow up (RR of 1.11 [CI 0.75 to 1.70]) [14]. Longer follow up in the PLCO still fails to prove any benefit for screening (RR of 1.04 [95\% CI $0.87-1.24]$ ) at 15 years [15]. The European trial (ERSPC) randomized 182,160 men between the ages of 50 and 74 years and found a statistically significant $21 \%$ reduction in prostate cancer mortality in men between 55 and 69 years (RR of 0.79 ; [CI $0.68-0.91 ; p=0.00]$ ) at 11 years follow up [16]. The aim of this study is to analyze the impact of the 2012 recommendation at our institution in terms of prostate cancer diagnosis and clinical staging.

\section{Methods}

After obtaining the institutional ethics committee's approval, we conducted a retrospective review of all patients who underwent prostate needle biopsies (PNB) at a single tertiary-care institution between January 2012 and December 2015. Patients were excluded from the analysis if they had been previously diagnosed with prostate cancer or had prostatic intraepithelial neoplasia (PIN) or atypical small acinar proliferation (ASAP) in the absence of any prostatic adenocarcinoma. We analyzed the total number of biopsies performed per year and the positive biopsy rate. For those patients with positive biopsies we recorded diagnostic PSA, digital rectal examination (DRE), ISUP grade group, nodal involvement and metastatic status. The Chi square test of independence was used to compare positive biopsy rates, Mann-Whitney $U$ test was used to compare prebiopsy PSA and Chi square Mantel-Haenszel test (linear by linear) for temporal tendency in the rest of the variables. Statistical significance was set at a $p$ value $<0.05$. Analysis was performed with SPSS 23.0 version.

\section{Results}

During the period studied, 1686 prostatic needle biopsies were performed. An overall $45 \%$ reduction was observed in the number of biopsies performed between the first and last year studied. Table 1 shows the total number of biopsies and the positivity rate per year. The percentage of positive biopsies were $25 \%$ in $2012,24 \%$ in 2013 , $38 \%$ in 2014 and $40 \%$ in 2015 , representing a significant increase $(p<0.0001)$.

The clinical presentation based on digital rectal examination (DRE), ISUP grade and distant metastasis were significantly worse in the later years studied. The lymph node involvement showed a non-statistically
Table 1 Population demographics and rate of positive biopsies

\begin{tabular}{lllll}
\hline & $\mathbf{2 0 1 2}$ & $\mathbf{2 0 1 3}$ & $\mathbf{2 0 1 4}$ & $\mathbf{2 0 1 5}$ \\
\hline Mean Age (SD) & $69.1(7.8)$ & $68.7(8.4)$ & $69.1(9.1)$ & $71(8.9)$ \\
Median PSA & 9 & 9.5 & 8.3 & 8.3 \\
Prior MRI (\%) & $10(6.5)$ & $29(25)$ & $43(43)$ & $54(40)$ \\
Positive biopsies (n) & 152 & 118 & 100 & 135 \\
Negative biopsies (n) & 446 & 378 & 163 & 196 \\
Total number of biopsies (n) & 598 & 496 & 263 & 329 \\
Positive biopsy rate (\%) & 25 & 24 & 38 & 40 \\
\hline
\end{tabular}

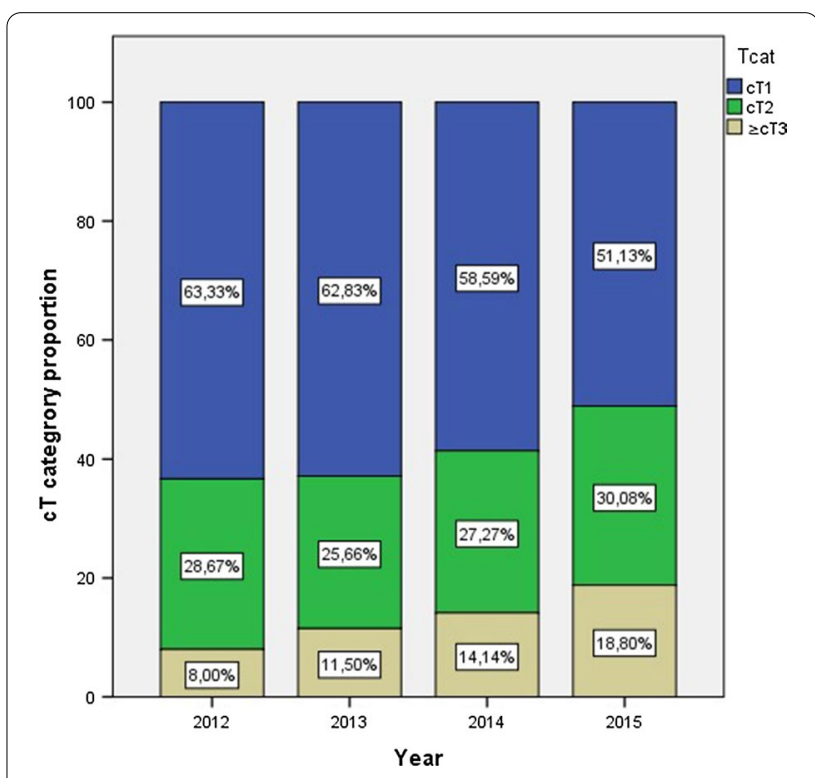

Fig. 1 Clinical stage (DRE)/year

significant increase and the PSA value at diagnosis did not show any difference throughout the study period.

The proportion of clinical stage $\mathrm{T} 1$ and $\geq \mathrm{T} 3$ were $63.3 \%$ and $8.0 \%$ in $2012.62 .8 \%$ and $11.5 \%$ in $2013.58 .6 \%$ and $14.1 \%$ in $201451.6 \%$ and $18.8 \%$ in 2015 respectively $(p=0.005)$ as shown in Fig. 1. Figure 2 summarizes the ISUP distribution per year. A significantly higher ISUP grade was seen in the linear temporal trend test $(p=$ $<0.05)$.

Significant differences were observed in distant metastasis at diagnosis (linear by linear chi square test $p=0.024$ ) with a proportion of $8.8 \% .11 .2 \% .9 .3 \%$ and $18.6 \%$ each year (Fig. 3). An increasing trend in lymph node involvement was observed with a proportion of $10.8 \% .13 .1 \% .11 .3 \%$ and $18.6 \%$ yearly. However, these differences did not meet conventional levels of statistical significance $(p=0.09)$. 


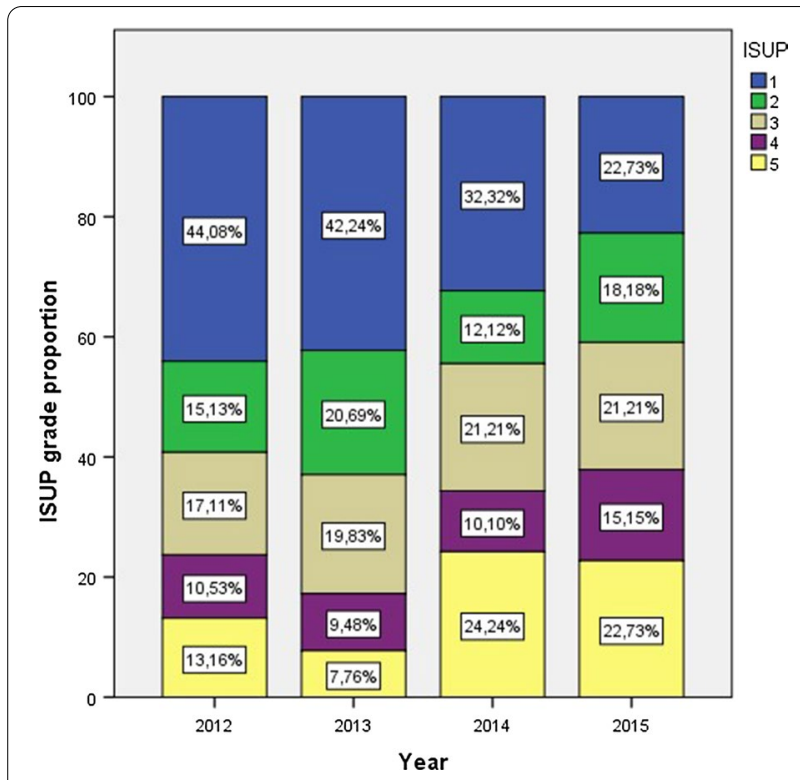

Fig. 2 ISUP distribution/year

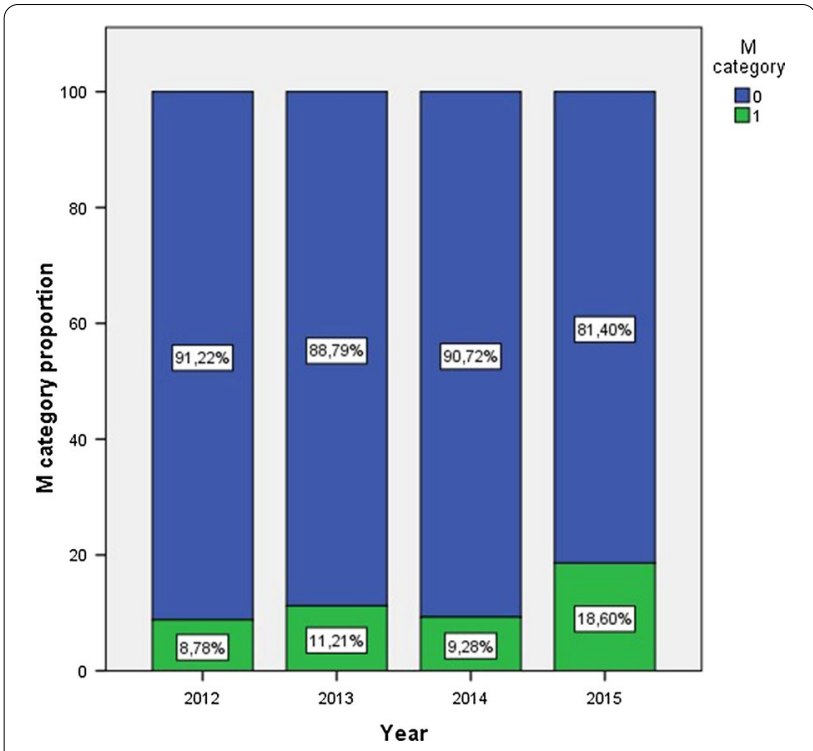

Fig. 3 Distant metastasis at diagnosis/year

Surprisingly, the median PSA was $9.0 \mathrm{ng} / \mathrm{dl}$ (ICR 6.114.3) for 2012; $9.5 \mathrm{ng} / \mathrm{dl}$ (ICR 6.3-23) for 2013; $8.3 \mathrm{ng} /$ dl (ICR 5.9-17) for 2014 and $8.3 \mathrm{ng} / \mathrm{dl}$ (ICR 6.01-21) for 2015 (Fig. 4). This difference in PSA values did not show a statistically significant difference $(p=0.627)$.

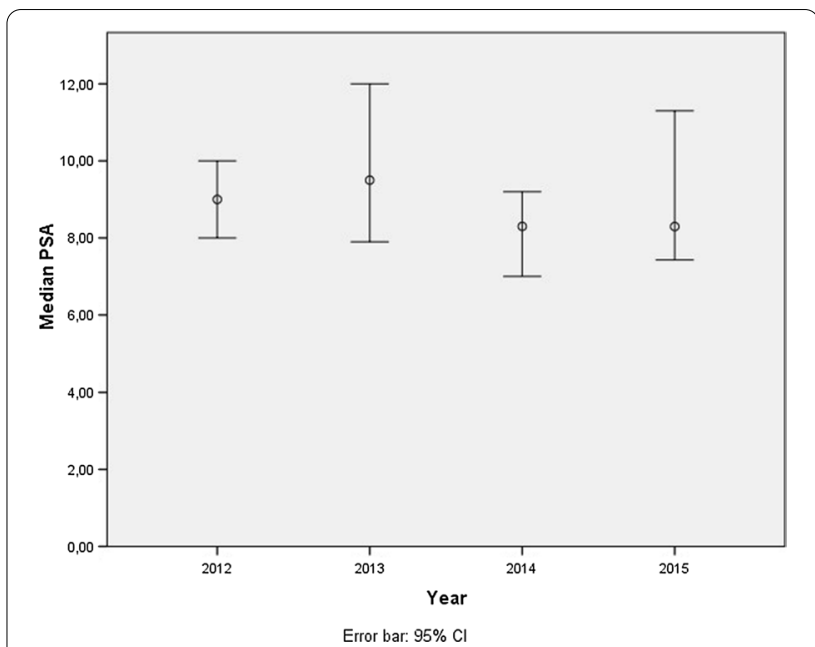

Fig. 4 Annual median PSA

\section{Discussion}

After the recommendation against massive prostate cancer screening by PSA, many studies have shown an increase in the diagnosis of high grade, locally advanced and metastatic prostate cancer [22-24]. Our results showed a significant impact of the screening policies, with a $45 \%$ decrease in the total number of biopsies performed per year and a significant increase in positive biopsy rates between 2012 and 2015. Our results confirm the findings of other groups that also found a significant decrease in the median number of biopsies $[25,26]$ and a $29 \%$ increase in positive biopsy rate [26]. Contrary to what we expected, our study was not able to show a significant increase in PSA at initial presentation, which was a constant in our examination of the literature [23, 2830]. Although we are not able to provide a definite explanation for this finding, we believe it might occur because of the different derivation criteria of the associated centers, different levels of compliance with the indication not to perform PSA screening and the rising use of prebiopsy MRI in the studied period.

We observed a significant increase in local tumoral aggressiveness, mostly because of an increase in the clinical staging cT2-4, and an increase in ISUP 4 and 5 . In their study, Banjeri et al., reported similar findings, with higher clinical stage (cT2b, $p=0.003$; cT2c-3a, $p=0.027$ ) and with D'Amico high risk scores $(p=0.036)$ after the USPTF recommendation [29]. We analyzed histological aggressiveness using the ISUP grading system. Several authors reported their results using the Gleason score and found a significant increase in grade [26, 30, 31, 41]. This increase in the diagnostic Gleason score has also been confirmed in the final pathology for radical prostatectomy [32]. 
We identified a significant increase in metastatic prostate cancer at the time of initial diagnosis, which, in our opinion, is the most important negative consequence of the implementation of non-screening recommendations. Our data supports the results described by other authors showing an increased incidence of metastatic prostate cancer at time of diagnosis. Bernstein et al., analyzing the SEER database, reported that in men $\geq 75$ years old, the diagnosis of distant metastases increased in 2012 compared with 2011 (IR 1.13, 95\% CI 1.02-1.24, $p<0.05$ ) [33]. Using the same database, $\mathrm{Hu}$ et al., confirmed this increase between 2010 and 2013 both in men $<75$ years (2.7\%; $95 \% \mathrm{CI}, 2.5 \%-2.9 \%$ vs. $4.0 \%$; $95 \%$ CI $3.8-4.2 \%)$ and $>75$ years $(6.6 \%$; $95 \%$ CI $6.2-7.0 \%$ vs. $12.0 \%$; $95 \%$ CI 11.2-12.7\%) [34]. In a population-based data review from 18 SEER registries, Dalela et al., noted that the incidence of metastatic prostate cancer increased significantly between the years 2009 and 2013 at a rate of 3.1\% per year $(p<0.05)$ [35]. Interestingly, Weiner et al., found that the increase in the annual incidence of metastatic prostate cancer was higher among men aged 55-69 years [36]. This is especially worrisome, because this is the group most likely to benefit from definitive treatment. We failed to confirm a significant increase in pelvic lymph node metastasis, although we observed a rising trend, similar to the results obtained by Blair et al. It is worth noting that these results contrast with those reported by Bernstein et al., who, by analyzing the SEER database, showed a significant increase in pelvic lymph node metastasis between 2004 and 2014 (from 54.1 to 79.5 per million men (IR 1.47, 95\% CI 1.33-1.62, $p<0.01$ ) [33].

Updated results from the ERSPC trial confirm the risk reduction of developing metastasis (HR 0.70; 95\% CI $0.60-0.82 ; p=0.001$ ) and PCa mortality, with a lower number of men needing to be invited for screening and diagnosis to prevent prostate cancer death (570 and 18 respectively) [37,38]. It is important to mention that, in a predictive model, discontinuation of screening eliminates all overdiagnoses, but it doubles metastatic cases at presentation and increases prostate cancer deaths by $13-20 \%$ [39]. Different models for PCa screening have been developed, taking into account PSA and age, as well as other secondary tests, such as markers or imaging tests, prior to biopsy [40].

Although our study provides important information about the impact of the 2012 recommendation on PSA screening in our population, we are aware of its limitations. In addition to its retrospective design and inherent biases, as a tertiary center with different associated centers we do not know the full level of penetration of the recommendation and the exact time of adoption in primary health centers. In addition, there could be a selection bias as the patients included in the study were not segregated as to whether they are on a screening or nonscreening protocol for PNB.

\section{Conclusions}

After the recommendation against PSA screening, the diagnostic profile of prostate cancer has changed in our tertiary care institution, with prostate cancer being diagnosed at a higher clinical stage, with increased histological aggressiveness and increased risk of metastatic disease. Such findings should favor a PSA- based screening policy for early detection of PCa. Advancing in this direction, different urological societies are working to implement prostate cancer screening for the general population.

\section{Abbreviations}

PSA: prostate specific antigen; DRE: digital rectal exam; PIN: prostate intraepithelial neoplasia; ASAP: atypical small acinar proliferation; PNB: prostate needle biopsy.

\section{Authors' contributions}

$A V, M R$ and $A A$ have given substantial contributions to the conception or the design of the manuscript, TA, CM and JD to acquisition, analysis and interpretation of the data. All authors have participated in drafting the manuscript, author AA revised it critically. All authors read and approved the final version of the manuscript. All authors contributed equally to the manuscript and read and approved the final version of the manuscript.

\section{Funding}

The authors certify that there is no funding is received for the manuscript writing and development.

\section{Availability of data and materials}

The data supporting the conclusions used and/or analyzed in this study are available from the corresponding author by request.

\section{Consent for publication}

The data do not contain any information that could identify the patient, therefore consent for publication was waived.

\section{Ethics approval and consent to participate}

This was a retrospective study approved by the Hospital Clinic of Barcelona ethical committee (CEIm). Informed consent was waived.

\section{Competing interests}

The authors declare that they have no competing interests.

\section{Author details}

${ }^{1}$ Urology Department, Hospital Clínic de Barcelona, C/ Villarroel, 170, 08036 Barcelona, Spain. ${ }^{2}$ Urology Department, Hospital Fuerza Aérea de Chile, Santiago, Chile. ${ }^{3}$ Pathology Department, Hospital Clínic de Barcelona, Barcelona, Spain.

Received: 24 September 2020 Accepted: 22 January 2021 Published online: 08 February 2021

References

1. Ferlay J, Ervik M, Lam F, Colombet M, Mery L, Piñeros M, Znaor A, Soerjomataram I, Bray F. Global Cancer Observatory: Cancer Today. Lyon, France: International Agency for Research on Cancer; 2018. Available from: https://gco.iarc.fr/today. Accessed 04 Nov 2019. 
2. Siegel R, Naishadham D, Jemal A. Cancer statistics, 2012. CA Cancer J Clin. 2012;62:10.

3. Ferlay J, Colombet M, Bray F. Cancer Incidence in Five Continents, Cl5plus: IARC CancerBase No. 9 [Internet]. Lyon, France: International Agency for Research on Cancer; 2018. Available from: http://ci5.iarc.fr

4. Brawley OW. Trends in prostate cancer in the United States. J Natl Cancer Inst Monogr. 2012;2012(45):152-6.

5. Center MM, Jemal A, Lortet-Tieulent J, Ward E, Ferlay J, Brawley O, et al. International variation in prostate cancer incidence and mortality rates. Eur Urol. 2012;61:1079-92.

6. National Cancer Institute. Cancer stat facts: prostate cancer. https://seer. cancer.gov/statfacts/html/prost.html. Accessed 8 Mar 2018

7. Heijnsdijk EAM, der Kinderen A, Wever EM, Draisma G, Roobol MJ, de Koning $\mathrm{HJ}$. Overdetection, overtreatment and costs in prostate-specific antigen screening for prostate cancer. Br J Cancer. 2009;101:1833-8.

8. Draisma G, Etzioni R, Tsodikov A, Mariotto A, Wever E, Gulati R, et al. Lead time and overdiagnosis in prostate-specific antigen screening: importance of methods and context. JNCI. 2009;101:374-83.

9. Gulati R, Wever EM, Tsodikov A, Penson DF, Inoue LY, Katcher J, et al. What if I don't treat my PSA-detected prostate cancer? Answers from three natural history models. Cancer Epidemiol Biomarkers Prev. 2011;20:740-50.

10. Carlsson S, Aus G, Wessman C, Hugosson J. Anxiety associated with prostate cancer screening with special reference to men with a positive screening test (elevated PSA): results from a prospective, populationbased, randomised study. Eur J Cancer. 2007:43:2109-16.

11. Raaijmakers R, Kirkels WJ, Roobol MJ, Wildhagen MF, Schroder FH. Complication rates and risk factors of 5802 transrectal ultrasound-guided sextant biopsies of the prostate within a population-based screening program. Urology. 2002;60:826-30.

12. Alivizatos G, Skolarikos A. Incontinence and erectile dysfunction following radical prostatectomy: a review. ScientificWorldJournal. 2005;13(5):747-58.

13. Moyer VA, U.S. Preventive Services Task Force. Screening for prostate cancer: U.S. Preventive Services Task Force Recommendation Statement. Ann Intern Med. 2012;157:120-34.

14. Andriole GL, Crawford ED, Grubb RL 3rd, Buys SS, Chia D, Church TR, PLCO Project Team, et al. Mortality results from a randomized prostate-cancer screening trial. N Engl J Med. 2009;360:1310-9.

15. Pinsky PF, Prorok PC, Yu K, Kramer BS, Black A, Gohagan JK, et al. Extended mortality results for prostate cancer screening in the PLCO trial with median follow-up of 15 years. Cancer. 2017;123(4):592-9.

16. Schröder FH, Hugosson J, Roobol MJ, Tammela TL, Ciatto S, Nelen V, ERSPC Investigators, et al. Prostate-cancer mortality at 11 years of followup. N Engl J Med. 2012;366(11):981-90.

17. Kearns JT, Holt SK, Wright JL, Lin DW, Lange PH, Gore JL. PSA screening, prostate biopsy, and treatment of prostate cancer in the years surrounding the USPSTF recommendation against prostate cancer screening. Cancer. 2018;124(13):2733-9.

18. Khairnar R, Mishra M, Onukwugha E. Impact of United States Preventive Services Task Force Recommendations on utilization of prostate-specific antigen screening in medicare beneficiaries. Am J Clin Oncol. 2018 Feb 16.

19. Olsson CA, Lavery HJ, Yadav KK, Anderson AE, Kapoor D. Histologic Changes in prostate cancer detected subsequent to the 2012 United States Preventive Services Task Force (USPSTF) Prostate Cancer Screening Recommendation. Rev Urol. 2018;20(3):125-30

20. Kelly SP, Anderson WF, Rosenberg PS, Cook MB. Past, current, and future incidence rates and burden of metastatic prostate cancer in the United States. Eur Urol Focus. 2018;4(1):121-7.

21. Ahlering T, Huynh LM, Kaler KS, Williams S, Osann K, Joseph J, et al. Unintended consequences of decreased PSA-based prostate cancer screening. World J Urol. 2019;37(3):489-96.

22. Leyh-Bannurah SR, Karakiewicz PI, Pompe RS, Preisser F, Zaffuto E, Dell'Oglio P, et al. Histologic changes in prostate cancer detected subsequent to the 2012 United States Preventive Services Task Force (USPSTF) Prostate Cancer Screening Recommendation. Rev Urol. 2018;20(3):125-30.

23. Tam AW, Khusid J, Inoyatov I, Becerra AZ, Davila J, Chouhan JD, et al. Changes observed in prostate biopsy practices in an inner-city hospital with a high risk patient population following the 2012 USPSTF PSA screening recommendations. Int Braz J Urol. 2018;44(4):697-703.

24. Baccaglini W, Cathelineau X, Araújo Glina FP, Medina LG, Sotelo R, Carneiro $A$, et al. Screening: actual trends on PSA marker. When, who, how? Arch Esp Urol. 2019;72(2):98-103.

25. Bhindi B, Mamdani M, Kulkarni GS, Finelli A, Hamilton RJ, Trachtenberg J, et al. Impact of the U.S. Preventive Services Task Force recommendations against prostate specific antigen screening on prostate biopsy and cancer detection rates. J Urol. 2015;193(5):1519-24.

26. Gejerman G, Ciccone P, Goldstein M, Lanteri V, Schlecker B, Sanzone J, et al. US Preventive Services Task Force prostate-specific antigen screening guidelines result in higher Gleason score diagnoses. Investig Clin Urol. 2017;58(6):423-8

27. Cohn JA, Wang CE, Lakeman JC, Silverstein JC, Brendler CB, Novakovic $\mathrm{KR}$, et al. Primary care physician PSA screening practices before and after the final U.S. Preventive Services Task Force recommendation. Urol Oncol. 2014;32(1):23-30

28. Aslani A, Minnillo BJ, Johnson B, Cherullo EE, Ponsky LE, Abouassaly R. The impact of recent screening recommendations on prostate cancer screening in a large health care system. J Urol. 2014;191(6):1737-42.

29. Banerji JS, Wolff EM, Massman JD 3rd, Odem-Davis K, Porter CR, Corman JM. Prostate needle biopsy outcomes in the Era of the US Preventive Services Task Force Recommendation against prostate specific antigen based screening. J Urol. 2016;195(1):66-73.

30. Blair BM, Robyak H, Clark JY, Kaag MG, Lehman EB, Raman JD. Impact of United States Preventive Services Task Force recommendations on prostate biopsy characteristics and disease presentation at a tertiary-care medical center. Prostate Int. 2018;6(3):110-4

31. Zakaria AS, Dragomir A, Brimo F, Kassouf W, Tanguay S, Aprikian A Changes in the outcome of prostate biopsies after preventive task force recommendation against prostate-specific antigen screening. BMC Urol. 2018;18(1):69

32. Gaylis FD, Choi JE, Hamilton Z, Dato P, Cohen E, Calabrese R, et al. Change in prostate cancer presentation coinciding with USPSTF screening recommendations at a community-based urology practice. Urol Oncol. 2017:35(11):663-70

33. Bernstein AN, Shoag JE, Golan R, Halpern JA, Schaeffer EM, Hsu WC, et al. Contemporary incidence and outcomes of prostate cancer lymph node metastases. J Urol. 2018;199(6):1510-7.

34. Hu JC, Nguyen P, Mao J, Halpern J, Shoag J, Wright JD, et al. Increase in prostate cancer distant metastases at diagnosis in the United States. JAMA Oncol. 2017;3:705-7.

35. Dalela D, Sun M, Diaz M, Karabon P, Seisen T, Trinh QD, et al. Contemporary trends in the incidence of metastatic prostate cancer among US men: results from nationwide analyses. Eur Urol Focus. 2019;5(1):77-80.

36. Weiner AB, Matulewicz RS, Eggener SE, Schaeffer EM. Increasing incidence of metastatic prostate cancer in the United States (2004-2013). Prostate Cancer Prostatic Dis. 2016;19(4):395-7.

37. Schröder FH, Hugosson J, Carlsson S, Tammela T, Määttänen L, Auvinen $A$, et al. Screening for prostate cancer decreases the risk of developing metastatic disease: findings from the European Randomized Study of Screening for Prostate Cancer (ERSPC). Eur Urol. 2012;62(5):745-52.

38. Hugosson J, Roobol MJ, Månsson M, Tammela TLJ, Zappa M, Nelen V, et al. A 16-yr follow-up of the European Randomized Study of Screening for Prostate Cancer. Eur Urol. 2019;76(1):43-51.

39. Gulati R, Tsodikov A, Etzioni R, Hunter-Merrill RA, Gore JL, Mariotto AB, et al. Expected population impacts of discontinued prostate-specific antigen screening. Cancer. 2014;120(22):3519-26.

40. Carlsson SV, Vickers AJ. Screening for prostate cancer. Med Clin North Am. 2020;104(6):1051-62. https://doi.org/10.1016/.mcna.2020.08.007.

41. Clements MB, Abdalla B, Culp SH, Costabile RA, Krupski TL. Prostate cancer characteristics in the US Preventive Services Task Force Grade D Era: a single-center study and meta-analysis. Urol Int. 2020;104(9-10):692-8. https://doi.org/10.1159/000507656.

\section{Publisher's Note}

Springer Nature remains neutral with regard to jurisdictional claims in published maps and institutional affiliations. 